\title{
Lenient computation in controlling the nonlinear system based on adaptive error optimisation in microgrid
}

\author{
T. Yuvaraja* and K. Ramya \\ Department of EEE, \\ Sri Sai Ram College of Engineering, \\ Bangalore City, India \\ Email: yuvarajastr@gmail.com \\ Email: ramyaj.k14@gmail.com \\ *Corresponding author
}

\begin{abstract}
This manuscript describes the hybrid learning algorithm for training the error optimisation in an MIMO nonlinear system. The automated controller is designed using lenient computation technique with a Levenberg-Marquardt training algorithm. The designed controller is interfaced to a microgrid which has renewable energy sources like solar, wind, fuel cell, or smart battery as input and the output power generated by these sources can be utilised for various grid and atomised applications. The erudition capability and designing methodology of adaptive networks and sturdiness of PID controllers are described. Finally, the study illustrates an offline mode comparison of PID-based ANFIS and neural controllers in terms of settling time, steady state error and overshoot.
\end{abstract}

Keywords: lenient computation; proportional-integral-derivative; PID; ANFIS PID; ANN ARX model; neural network; renewable energy sources; microgrid.

Reference to this paper should be made as follows: Yuvaraja, T. and Ramya, K. (2018) 'Lenient computation in controlling the nonlinear system based on adaptive error optimisation in microgrid', Int. J. Intelligent Machines and Robotics, Vol. 1, No. 1, pp.5-15.

Biographical notes: T. Yuvaraja obtained his BE degree from Anna University, Chennai in 2009. He obtained his ME degree from Anna University, Chennai in 2012 and $\mathrm{PhD}$ degree in the Department of Electrical and Electronics Engineering from Meenakshi Academy of Higher Education and Research, Chennai, India in 2017. Currently, he is an Assistant Professor, Department of Electrical and Electronics Engineering, Sri Sai Ram College of Engineering, Bangalore, India. His research interests include power quality issues, high power converters, electromagnetic transients in power systems, power system dynamics and control and power electronics technologies for microgrid and renewable energy applications. He is a professional member of IEEE, ISTE, IAENG.

K. Ramya obtained her BE degree from Periyaar University, Salem in 2003. She obtained her MTech degree from Kuppam Engineering College; Affilated to JNTU, Anathapur, Andra Pradesh in 2015 and currently pursuing her $\mathrm{PhD}$ in Energy Studies from Periyar University, Salem. She is working as an Assistant Professor/EEE, at Sri Sairam College of Engineering, Bangalore, India. Her 
area of interest is power electronics. She is a professional member of ISTE, IAENG, and ISRD. She has received Best Academic Excellence Award for more than ten times for the academic years 2008 to 2015 .

\section{Introduction}

Triple stage inverted pendulum belongs to a category of highly unstable and underactuated system which exhibits highly nonlinear behaviour due to its complex dynamics (Gluck et al., 2013). These systems are testing bed platforms for comparing various control algorithms and strategies (Kizir et al., 2010; Henmi et al., 2015). The system resembles dynamics of humanoid robot, flexible space structures and therefore attracts interest of many researchers (Mao et al., 2013; Eltohamy and Kuo, 2010). Farwig and Unbehauen (1990) examined stabilisation of triple link inverted pendulum based on state space approach. The authors utilised a computer-aided design package.

A proportional-integral-derivative (PID)-neural adaptive controller for stabilisation of triple inverted pendulum was proposed by Liang et al. (2010). The control law for PID was obtained using back-propagation algorithm and Lyapunov method was applied for learning of adaptive controllers. In a study by Ling et al. (2011) comparison of single neuron adaptive proportional differential (SNPD) control and LQR control for stabilisation of triple inverted pendulum was performed. The results showed that SNPD strategy provides better stability and enhances anti-jamming capacity of the system. Zhang et al. (2012) designed a variable gain LQR controller for control of three stage inverted pendulum. The authors proposed a new algorithm based on Schur method for solution of Riccati equation. Real time experiments were performed to demonstrate the proposed control. According to Huang et al. (2012) an intelligent control based on combination of neural network and genetic algorithm (GA) can be applied to simulate a triple inverted pendulum system. The results showed that proposed control provides faster convergence and accompanies less iterations. Molazadeh et al. (2014) designed a LQR controller for control of triple inverted pendulum. The tuning of LQR gains was achieved using fuzzy logic, GA and GA-particle swarm optimisation (PSO) algorithm. The results showed superiority of fuzzy controller over other two controllers.

In a study by Zhang et al. (2015) a PID neural network (PIDNN) controller was optimised using cloud genetic algorithm (CGA) for control of three-stage inverted pendulum. It was observed that CGA provides faster convergence and avoids premature convergence phenomenon of GAs. The study further presented a three dimensional animated simulation to verify proposed control. Chen and Theodomile (2016) designed a feedback weight matrix of linear quadratic regulator (LQR) optimal control and feedback parameters of linear optimal control for determining configuration of fuzzy controller. The fuzzy controller was further applied to control a three-stage inverted pendulum. The results showed that the proposed controller selects simple parameters and exhibits good performance. This paper presents a new approach of designing PID-based ANFIS and neural controllers for stabilisation of triple link inverted pendulum on cart. The paper describes in detail designing procedure of proposed controllers. The study compares linear and constant type MFs of different shapes. The performance of MFs was judged based on their respective training error tolerances. The relation between number of MFs 
and training error of ANFIS has also been demonstrated. The performances of controllers were compared in terms of three performance parameters namely settling time, maximum overshoot and steady state error.

Teekaraman and Mani (2014a) developed fuzzy controlled-based distributed generation unit in grid operated in islanded mode with storage system. The simulation results validate the model and robustness of the proposed control scheme to changes in system loading and power factor. Teekaraman and Mani (2015b) incorporated a decoupling algorithm and notch filter with three level hysteresis controllers under stiff symmetrical and asymmetrical grid conditions. Also the entire concept is analysed in dq reference frame. Teekaraman and Mani (2015a) concluded that distributed generation units in islanded mode controlled by fuzzy model in a reference frame promptly and establish legitimacy of the model and robustness of the control scheme to change system loading and power factor. Teekaraman and Ramya (2016) implemented the solar energy with new controlling parameter in $\mu$ grid under partial shading condition for better stabilisation and optimisation. The dynamic control scheme is presented to analyse the performance of a three-phase grid-connected PV system and to enhance the dynamic stability limit with the change in atmospheric conditions by utilising the new control factor. Teekaraman and Mani (2014b) implemented multicarrier level shifted current control, at higher feed forward gain and hence better control characteristics. Also it can be controlled to feed the load real power with the balance real power being supplied from the grid. In addition to real power injection, the objective of load compensation is also achieved leading to a balanced, distortion free, and unity power factor source current.

\section{Lenient computing procedures}

An elaborate explanation of controller implemented for controlling the error in the proposed system is as follows.

\subsection{PID control}

PID controllers are the most prominent designed controllers which are frequently used as feedback (closed loop) in processing the system having resonance and unstable transfer function (Kaya et al., 2006). These are extremely robust controllers, easy to design and afford squat overshoot and minor settling time (Matusu and Prokop, 2016). The principle of PID controller is based on calculating an error value $e(t)$ which is a difference between desired output and measured value. The main aim is to minimise the error by regulating the control variable $u(t)$. A general representation of PID controller is given in equation (1) where $K_{p}, K_{d}$ and $K_{i}$ are proportional, derivative and integral gains respectively.

$$
u(t)=K_{p}\left[e(t)+\frac{1}{K_{i}} \int_{0}^{t} e(t) \cdot d t+K_{d} \frac{d}{d t} e(t)\right]
$$

The PID gains were obtained using trial and error approach and are stated in Table 1 at different stages of the system. The fine-tuning of the gain is done by changing the gain of one particular controller while gains of other controllers were kept unchanged. The process is repeated till satisfactory response of all controllers is achieved. 
Table 1 PID gains for different controllers in different stages

\begin{tabular}{lccc}
\hline & $K_{p}$ & $K_{i}$ & $K_{d}$ \\
\hline Source side & 100 & 0 & -10 \\
Transmission side & 1 & 0 & -1 \\
Distribution side & 1 & 0 & -1 \\
Grid side & 10 & 0 & -10 \\
\hline
\end{tabular}

\section{$2.2 \quad$ PID-based neural control}

ANN includes smart gen processing elements called neurons which are capable of adapting their weights according to a given datasets. Neural networks are very effective in situations where explicit knowledge of system and its analytical equations is not available (Yesildirek et al., 1996). The neural architecture comprises three different layers which are presented to different systems (system 1, system 2, and system 3). Firstly, the inputs are collected at input layer after which processing is performed at hidden layer and finally the output is obtained at output layer. PID-based neural control architecture is shown in Figure 1.

Figure 1 PID neural control architecture (see online version for colours)

\section{MIIMO System Configuration in ANN Approach}

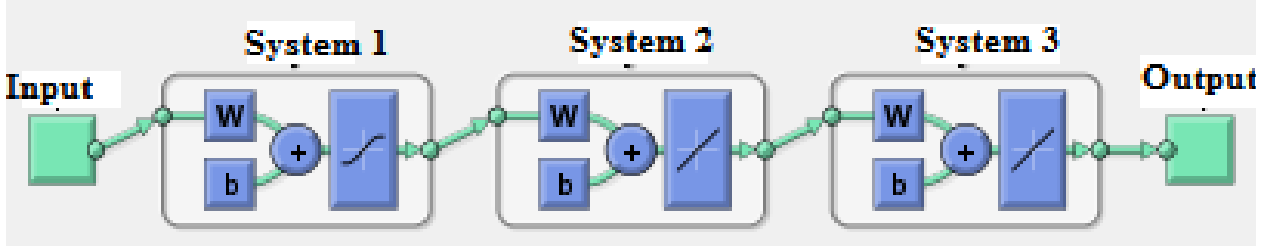

\subsection{MIMO modelling of microgrid using ANN ARX model}

ARX model is an important property of regressors and it has been implemented in the designed nonlinear system. The output of an ARX model is a function of regressors. The function of ARX model has both linear system configuration and nonlinear system configuration. The net ARX model output is the sum of the outputs of the two systems and an subset of errors is considered as regressors to enter the nonlinear block. These regressors are referred to as 'nonlinear regressors'. Nonlinear are specified as vector regressor indices.

Figure 2 depicts the ANN training algorithm in controller performance for optimising the error in the designed network. The current flowing through the path is calculated theoretically and is compared with the measured value through iteration process algorithm. The algorithm used is Levenberg-Marquardt training algorithm. The Levenberg-Marquardt algorithm is designed using the approach of second-order system without computing the Hessian matrix. The performance error optimisation function is obtained in the form of sum of squares and if the same is used in training feedforward networks then the Hessian matrix can be approximated as 


$$
\begin{aligned}
& H=K^{T} K \\
& g=K^{T} e
\end{aligned}
$$

where $K$ is matrix that contains first order derivative of the system errors with respect to the weights and biases, and $e$ is a vector of network errors.

Figure 2 Controller performance in neural training algorithm (see online version for colours)

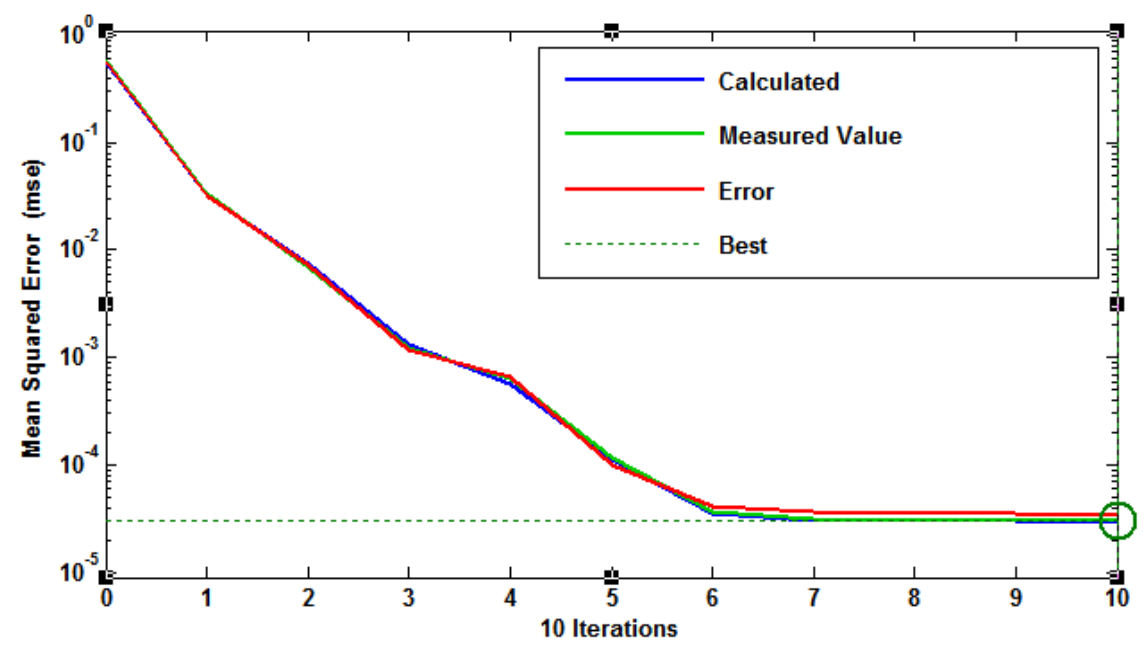

\subsection{PID-based ANFIS control}

ANFIS is an adaptive learning network which applies hybrid learning algorithms for tuning of the MFs and fuzzy rules (Qiang et al., 2008). ANFIS imbibes fuzzy logic ability of if-then rules and learning capacity of neural networks (Al-Hmouz et al., 2012). Tuning of ANFIS controllers was performed based on datasets (147 nos.) collected from results of PID controllers. The shape and number of MFs play a significant role during learning and tuning of ANFIS. Therefore, we have considered two different shapes of MFs.

Figure 3 Nonlinear regressor analysis for current target (see online version for colours)
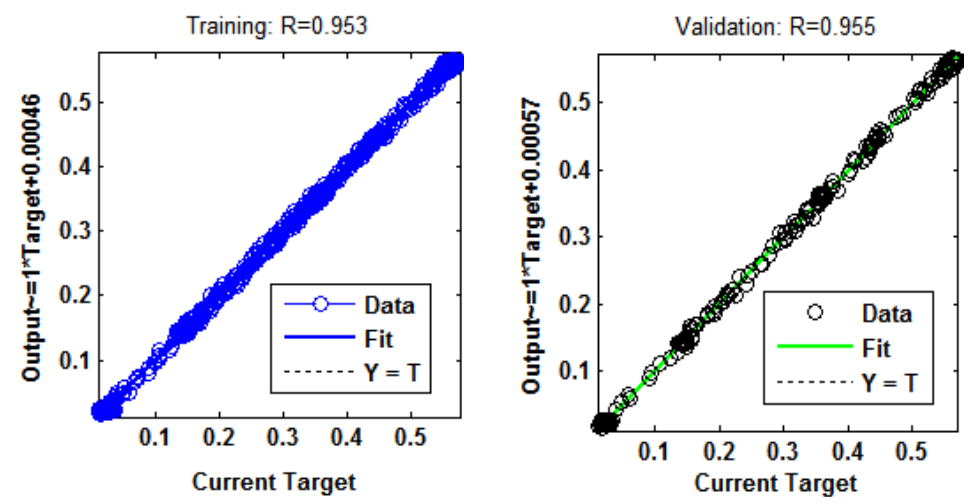
Figure 3 Nonlinear regressor analysis for current target (continued) (see online version for colour)
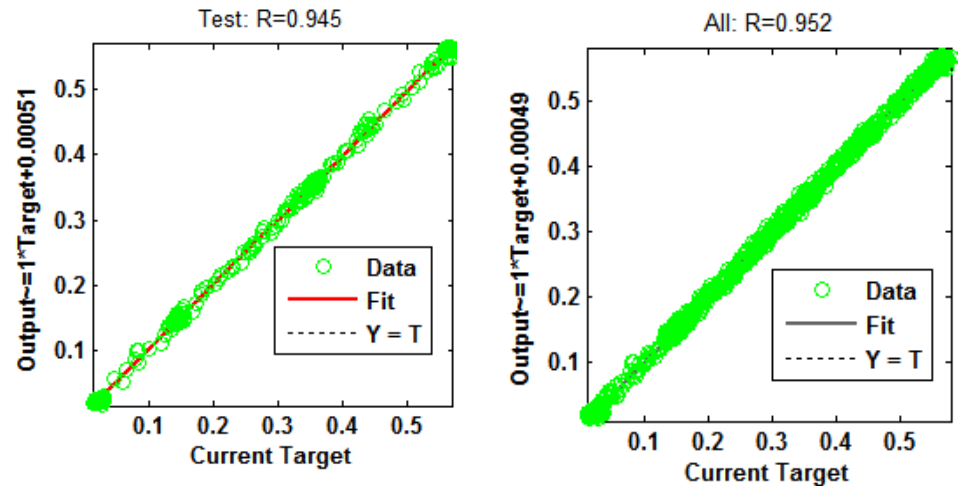

Figure 4 PID controller output using ANFIS controller (see online version for colours)

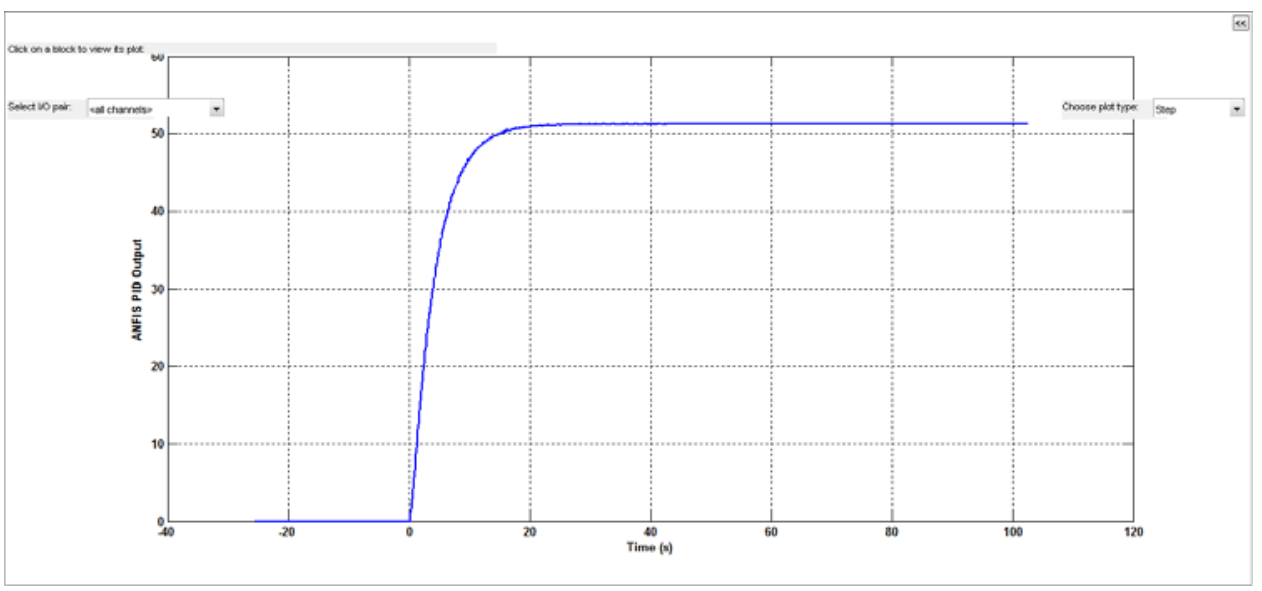

Figure 5 Gain prediction with PID and ANFIS PID controller (see online version for colours)

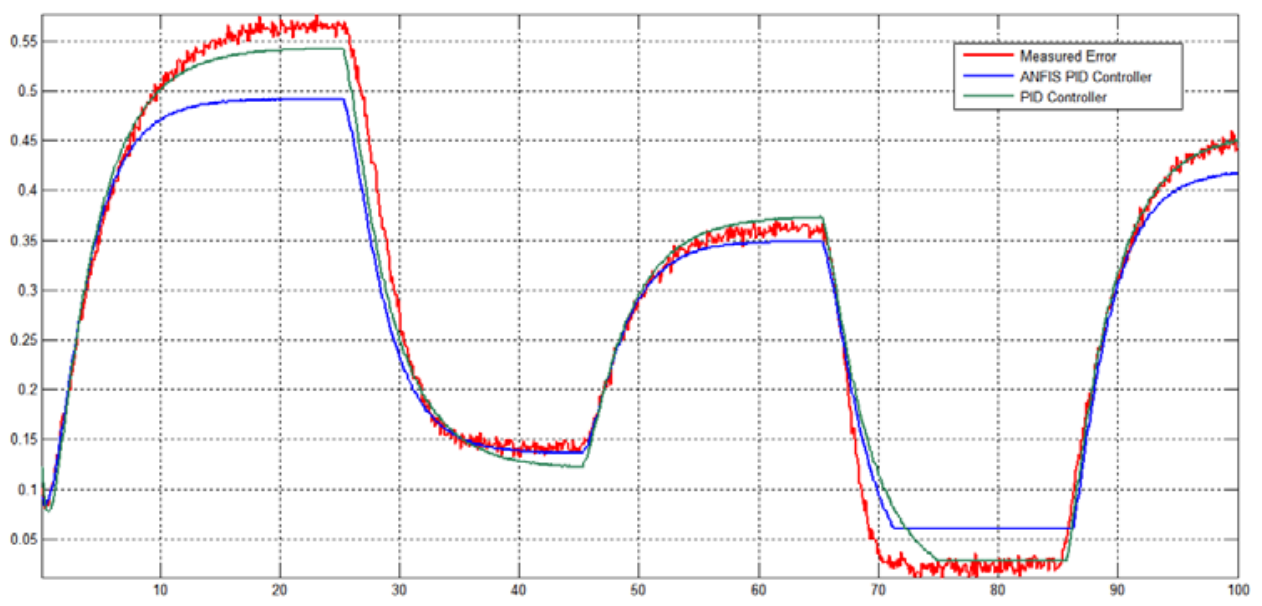




\section{Result analysis}

Regressors 1:

$$
\begin{aligned}
& y 1(t-1) \\
& y 1(t-2) \\
& y 1(t-3) \\
& y 1(t-4) \\
& y 1(t-5) \\
& u 1(t-3)
\end{aligned}
$$

Regressors 2:

$$
\begin{aligned}
& y 1(t-1) \\
& y 1(t-2) \\
& y 1(t-3) \\
& y 1(t-4) \\
& y 1(t-5) \\
& u 1(t-3)
\end{aligned}
$$

Nonlinear regressors:

$$
\begin{aligned}
& y 1(t-1) \\
& y 1(t-2) \\
& u 1(t-3) \\
& \text { ans }=
\end{aligned}
$$

$$
6
$$

Nonlinear regressors: $u 1(t-3)$

Searching for best nonlinear regressors

Tested regressor combinations: 64/64

Selecting wavelets: $100 \%$

ans $=$

$$
46
$$

Regressors:

$y 1(t-1)$

$y 1(t-2)$

$y 1(t-3)$

$y 1(t-4)$

$y 1(t-5)$

$u 1(t-3)$ 
Figure 6 Regressors analysis in nonlinear sector (see online version for colours)

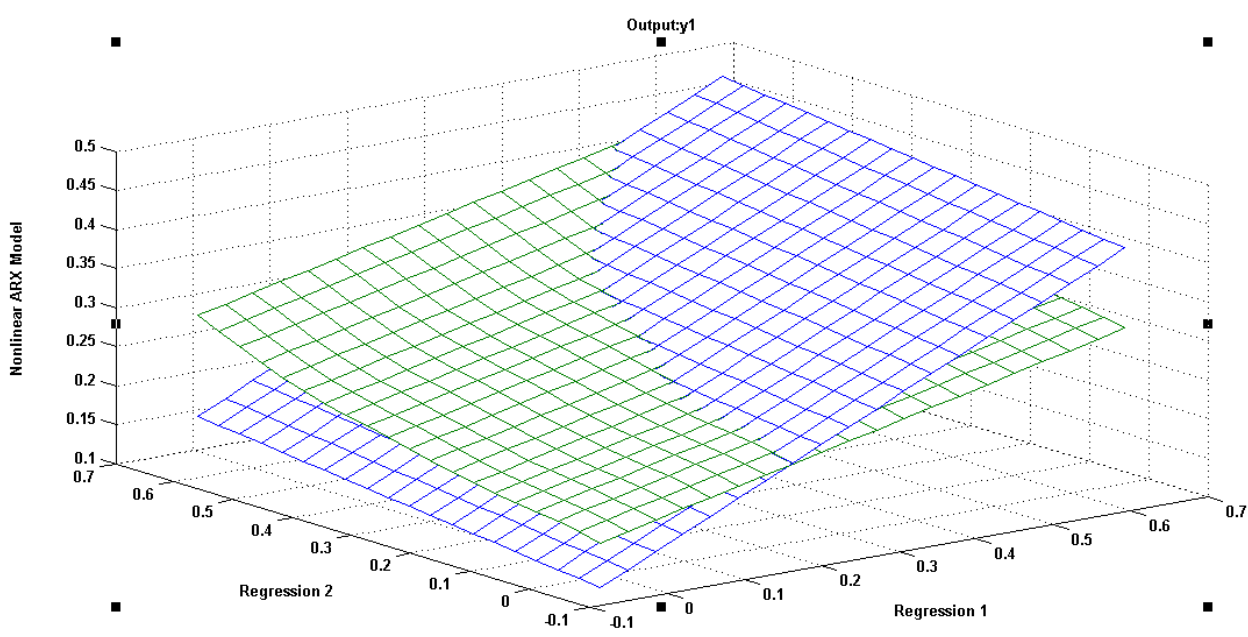

The above plotted charts clearly highlight that minimum training error was achieved using PID ANFIS controller using constant type Gauss2 MFs for all the controllers. The constant type Gauss2 MFs provide improved training error compared to linear type PID controller when the number of MFs is less and vice versa. Therefore, an optimal number and shape of MFs have to selected for better learning and training of controllers.

Table 2 Error tolerance for PID and ANFIS PID controller

\begin{tabular}{lccccc}
\hline \multirow{2}{*}{$\begin{array}{l}\text { Membership } \\
\text { functions }\end{array}$} & \multicolumn{2}{c}{ PID controller } & & \multicolumn{2}{c}{ PD ANFIS controller } \\
\cline { 2 - 3 } \cline { 5 - 6 } \cline { 5 - 6 } & Gauss & Gauss $2 m f$ & & Gauss & Gauss $2 m f$ \\
\hline 1 & 2.6452 & -2.1546 & & 0.00032088 & $3.1733 \mathrm{e}-005$ \\
2 & 3.4056 & -1.5962 & & 0.00020808 & $2.8441 \mathrm{e}-005$ \\
3 & 4.1661 & 0.0053 & & 0.00002088 & $2.5261 \mathrm{e}-005$ \\
4 & 4.9266 & 1.9515 & & 0.00021106 & 0.0016229 \\
5 & 5.6316 & 3.4279 & & 0.00023404 & $2.8753 \mathrm{e}-005$ \\
6 & 6.3591 & 4.5585 & & 0.00014889 & $1.7385 \mathrm{e}-005$ \\
7 & 7.0867 & 5.3282 & & 0.00010009 & 0.001776 \\
8 & 7.8142 & 5.7692 & & 0.00045389 & $2.9845 \mathrm{e}-005$ \\
9 & 8.2970 & 5.8651 & & 0.00014889 & 0.001743 \\
\hline
\end{tabular}

\section{Conclusions}

A comparative analysis is performed between PUD and ANFIS PID controller with different membership functions. Levenberg-Marquardt training algorithm is implemented in lenient computation technique. The study for the first time sets up selection criteria for selecting shape and number of MFs in determining error tolerances of adaptive controllers. It can be clearly observed from Table 2 that training errors achieved using Gauss 2 shape MFs of constant type were a minimum. The neural controllers were retuned 
until minimal MSE values and regression value was achieved. Simulation was done using MATLAB and led to better performance and robustness of ANFIS PID controller over other PID Controller techniques. The overshoot response of ANFIS PID controller is better and error optimisation is done with adaptive technique where the controller shows excellent steady state response.

\section{References}

Al-Hmouz, A., Shen, J., Al-Hmouz, R. and Yan, J. (2012) 'Modeling and simulation of an adaptive neuro fuzzy inference system (ANFIS) for mobile learning', IEEE Transactions on Learning Technologies, Vol. 5, No. 3, pp.226-237, doi: 10.1109/TLT.2011.36.

Awrejcewicz, J. and Kudra, G. (2007) 'The triple pendulum with barriers and the piston-connecting rod-crankshaft model', Journal of Theoretical and Applied Mechanics, Vol. 45, No. 1, pp.15-23.

Chen, W. and Theodomile, N. (2016) 'Simulation of a triple inverted pendulum based on fuzzy control', World Journal of Engineering and Technology, Vol. 4, No. 2, pp.267-272, doi: 10.4236/wjet.2016.42026.

Duran, M.J., Gallardo, S., Toral, S.L., Martinez-Torres, R. and Barreno, F.J. (2007) 'A learning methodology using Matlab/simulink for undergraduate electrical engineering courses attending to learner satisfaction outcomes', International Journal of Technology and Design Education, Vol. 17, No. 1, pp.55-73, doi: 10.1007/s10798-006-9007-z.

Eltohamy, K.G. and Kuo, C.Y. (2010) 'Nonlinear optimal control of a triple link inverted pendulum with single control input', International Journal of Control, Vol. 69, No. 2, pp.239-256.

Farwig, H.Z.M. and Unbehauen, H. (1990) 'Discrete computer control of a triple inverted pendulum', Optimal Control: Application and Methods, Vol. 11, No. 2, pp.157-171, doi: 10.1002/oca.4660110205.

Geidarov, P. (2015) 'Clearly defined neural network architecture', Optical Memory and Neural Networks, Vol. 24, No. 3, pp.209-219, doi: 10.3103/S1060992X15030054.

Gluck, T., Eder, A. and Kugi, A. (2013) 'Swing-up control of a triple pendulum on cart with experimental validation', Automatika, Vol. 49, No. 3, pp.801-808, doi: 10.1016/ j.automatica.2012.12.006.

Haouani, M., Lefebvre, D., Zerhouni, N. and El-Moudni, A. (2000) 'Neural networks implementations for modeling and control design of manufacturing systems', Journal of Intelligent Manufacturing, Vol. 11, No. 1, pp.29-40, doi: 10.1023/A: 1008947923697.

Henmi, T., Deng, M. and Inoue, A. (2015) 'Unified controller for swing-up control of parallel and serial double inverted pendulum systems', International Journal of Advanced Mechatronic Systems, Vol. 6, Nos. 2/3, pp.98-107.

Huang, X., Zhang, Y. and Zheng, J. (2012) 'Research of triple inverted pendulum based on neural network of genetic algorithm', Proceedings of 3rd International Conference on Advances in Swarm Intelligence, Shenzhen, China, pp.437-443, doi: 10.1007/978-3-642-30976-2_53.

Kaya, I., Tan, N. and Atherton, D.P. (2006) 'A refinement procedure for PID controllers', Electrical Engineering, Vol. 88, No. 3, pp.215-221, doi: 10.1007/s00202004-0276-9.

Kizir, S., Bingul, Z. and Oysu, C. (2010) 'Fuzzy control of a real time inverted pendulum system', Journal of Intelligent and Fuzzy Systems, Vol. 21, Nos. 1-2, pp.121-133, doi: 10.1007/978-3540-85563-7_85.

Li, H., Zhihong, M. and Jiayin, W. (2002) 'Variable universe adaptive fuzzy control on the quadruple inverted pendulum', Science in China Series E: Technological Sciences, Vol. 45, No. 2, pp.213-224, doi: 10.1360/02ye9026.

Liang, Y.Y., Cong, S. and Liu, H.W. (2010) 'PID-like neural network nonlinear adaptive control', Proceedings of 29th Chinese Control Conference, Beijing, China, pp.2144-2148. 
Ling, Z., Wei, Q. and Enrang, Z. (2011) 'A simulation research of nonlinear control method in triple inverted pendulum', Proceedings of International Conference on Informatics, Cybernetics and Computer Engineering, Melbourne, Australia, pp.595-602, doi: 10.1007/9783-642-25185-6 76.

Mao, L., Huang, J., Ding, F. and Wang, Y. (2013) 'Velocity control of mobile inverted pendulum', International Journal of Modeling, Identification and Control, Vol. 19, No. 1, pp.43-51.

Matusu, R. and Prokop, R. (2016) 'Computation of robustly stabilising PID controllers for interval systems', Springer Plus, Vol. 5, No. 1, pp.1-15, doi: 10.1186/s40064-016-2341-z.

Medrano-Cerda, G.A. (1997) 'Robust stabilization of a triple inverted pendulum cart', International Journal of Control, Vol. 68, No. 4, pp.849-865.

Medrano-Cerda, G.A., Eldukhri, E.E. and Cetin, M. (1995) 'Balancing and attitude control of double and triple inverted pendulums', Transactions of the Institute of Measurement and Control, Vol. 17, No. 3, pp.143-154, doi: 10.1177/014233129501700306.

Molazadeh, V.R., Banazadeh, A. and Shafieenejad, I. (2014) 'Design of the LQR controller and observer with fuzzy logic GA and GA-PSO algorithm for triple inverted pendulum and cart system', Proceedings of IEEE International Conference on Advanced Mechatronic Systems, Kumamoto, Japan, pp.295-300, doi: 10.1109/ICAMechS.2014.6911560.

Qiang, S., Zhou, Q., Gao, X.Z. and Yu, S. (2008) 'ANFIS controller for double inverted pendulum', Proceedings of 6th IEEE International Conference on Industrial Informatics, Daejeon, South Korea, pp.475-480, doi: 10.1109/INDIN.2008.4618147.

Qu, J., Wu, W. and Sun, J. (2004) 'Design and simulation of the fuzzy controller for the three stage inverted pendulum', Journal of Systems Simulation, Vol. 16, No. 3, pp.578-581.

Song, S.J., Moon, Y., Lee, D.H., Ahn, C.B., Jo, Y. and Choi, J. (2015) 'Comparative study of fuzzy PID control algorithms for enhanced position control in laparoscopic surgery robot', Journal of Medical and Biological Engineering, Vol. 35, No. 1, pp.34-44, doi: 10.1007/s40846-015003-1.

Sung, S.W. and Lee, J.B. (1999) 'On-line process identification and PID controller auto tuning', Korean Journal of Chemical Engineering, Vol. 16, No. 1, pp.45-55, doi: 10.1007/ BF02699004.

Teekaraman, Y. and Mani, G. (2014a) 'Fuzzy based analysis of inverter fed micro grid in islanding operation', International Journal of Applied Engineering Research, Vol. 9, No. 22, pp.16909-16916, ISSN 0973-4562.

Teekaraman, Y. and Mani, G. (2014b) 'Performance and measurement of current control schemes in grid connected inverters', Australian Journal of Basic and Applied Sciences, June, Vol. 8, No. 9, pp.163-170, AENSI, ISSN:1991-8178.

Teekaraman, Y. and Mani, G. (2015a) 'Fuzzy based analysis of inverter fed micro grid in islanding operation-experimental analysis', International Journal of Power Electronics and Drive System (IJPEDS), April, Vol. 5, No. 4, pp.464-469, ISSN: 2088-8694.

Teekaraman, Y. and Mani, G. (2015b) 'Multiple current control strategies for an optional operation of VBC linked to an ineffectual point in POER system beneath diversified grid conditions', International Journal of Soft Computing, Vol. 10, No. 2, pp.118-126,2015, ISSN: 1816-9503.

Teekaraman, Y. and Ramya, K. (2016) 'Vigorous simple most extreme force point tracker for PV battery charger', Environ Syst Res, Vol. 5, p.25, DOI 10.1186/s40068-016-0075-0.

$\mathrm{Xu}, \mathrm{T}$. and Zhang, C. (2014) 'Multi-level linear flexible inverted pendulum modeling', Applied Mechanics and Materials, Vol. 518, pp.290-296 [online] doi:10.4028/www.scientific.net/ AMM.518.290.

Yesildirek, A., Vandegrift, M.W. and Lewis, F.L. (1996) 'A neural network controller for flexiblelink robots', Journal of Intelligent and Robotic Systems, Vol. 17, No. 4, pp.327-329, doi: 10.1007/BF00571697. 
Zhang, X.L., Fan, H.M., Zang, J.Y., Zhao, L. and Hao, S. (2015) 'The stabilisation and 3D visual simulation of the triple inverted pendulum based on CGA-PIDNN', International Journal of Control, Automaton and Systems, Vol. 13, No. 4, pp.1010-1019, doi: 10.1007/s/2555-0140040-5.

Zhang, Y., Miao, Z., Li, H. and Nian, F. (2012) 'Stabilising the triple inverted pendulum by variable gain linear quadratic regulator', International Journal of Systems, Control and Communications, Vol. 4, No. 3, pp.208-233, doi: 10.1504/IJSCC.2012.048616. 